\title{
Desaturation During the 3-Minute Step Test Predicts Impaired 12-Month Outcomes in Adult Patients With Cystic Fibrosis
}

\author{
Anne E Holland PhD, Tshepo Rasekaba MSc, John W Wilson PhD, and Brenda M Button PhD
}

\begin{abstract}
BACKGROUND: The 3-minute step test is a simple test of exercise capacity for children with cystic fibrosis $(\mathrm{CF})$, but no data have been reported regarding its usefulness in adults or its prognostic value. OBJECTIVE: To determine the feasibility and acceptability of the 3-minute step test as a test of exercise capacity in adults with $\mathrm{CF}$ and whether test performance is associated with 12-month clinical outcomes. METHODS: From our out-patient clinic we prospectively recruited consecutive adult patients with $\mathrm{CF}$ in stable health. The 3-minute step test was conducted with a standardized protocol that included a $15-\mathrm{cm}$ high step and external pacing at $30 \mathrm{steps} / \mathrm{min}$. We measured heart rate, dyspnea, and $\mathrm{S}_{\mathrm{pO}_{2}}$. With multiple linear regression analyses we assessed the relationships between step-test performance and change in $\mathrm{FEV}_{1}$ and hospital days at 12 months. RESULTS: The participants were 101 adults: 56 male, mean \pm SD age $29 \pm 9$ years, percent-of-predicted $F E V_{1}$ $61 \pm 23 \%$, body mass index $22 \pm 4 \mathrm{~kg} / \mathrm{m}^{2}$. Only $42 \%$ of the participants with mild CF achieved $70 \%$ of the predicted maximum heart rate during the 3-minute step test, compared to $77 \%$ of those with $\mathrm{FEV}_{1}<60 \%$ of predicted. The 22 patients who desaturated to $<90 \%$ during the 3-minute step test had a larger number of hospital days over the following 12 months than did those who did not (median $28 \mathrm{~d}$ vs $11 \mathrm{~d}, P<.001$ ). Those who desaturated also had a greater $\mathrm{FEV}_{1}$ decline (mean difference $-117 \mathrm{~mL}, 95 \% \mathrm{CI}-215$ to $-19 \mathrm{~mL}$ ). Desaturation during the 3-minute step test was an independent predictor of both $\mathrm{FEV}_{1}$ decline and days spent in hospital. CONCLUSIONS: Desaturation during the 3-minute step test is associated with long-term pulmonary deterioration and more hospital days in adults with CF. The 3-minute step test may be a useful screening test for patients with moderate to severe CF lung disease, who require increased intervention and monitoring. Key words: cystic fibrosis; exercise test; prognosis; respiratory function tests. [Respir Care 2011;56(8):11371142. () 2011 Daedalus Enterprises]
\end{abstract}

\section{Introduction}

Assessment of exercise capacity is an important element of clinical management of adults with cystic fibrosis (CF). Higher levels of physical fitness are associated with better survival, ${ }^{1}$ and exercise training forms a critical part of the treatment regimen. ${ }^{2}$ It has been recommended that a com-

\footnotetext{
Dr Holland, Mr Rasekaba, and Dr Button are affiliated with the Physiotherapy Department, Alfred Hospital, Melbourne, Australia. Dr Wilson is affiliated with the Allergy, Immunology and Respiratory Medicine, Alfred Hospital, Melbourne, Australia. Dr Holland is also affiliated with the School of Physiotherapy, La Trobe University, Bundoora, Victoria, Australia. Drs Wilson and Button are also affiliated with the Department of Medicine, Monash University, Victoria, Australia.
}

Dr Holland presented a version of this paper at the North American Cystic Fibrosis Conference, held October 23-25, 2008, in Orlando, Florida. prehensive exercise assessment be performed at least annually in all patients with CF. ${ }^{3,4}$

There are a variety of methods available to measure exercise capacity. Tests of maximal exercise performance on a cycle ergometer provide a detailed cardiorespiratory assessment and valid prognostic information. ${ }^{1}$ However, these tests are complex, expensive, and may be onerous

\footnotetext{
Mr Rasekaba presented a version of this paper at the Thoracic Society of Australia and New Zealand Annual Scientific Meeting, held April 3-8, 2009, in Darwin Australia. Dr Button presented a version of this paper at the European Cystic Fibrosis Conference, held June 10-13, 2009, in Brest, France.

Correspondence: Anne E Holland PhD, Physiotherapy Department, Alfred Hospital, 99 Commercial Road, Melbourne, Victoria 3004 Australia. E-mail: a.holland@alfred.org.au.
}

DOI: $10.4187 /$ respcare.01016 
for patients. This has limited the application of maximal tests in clinical practice. Field walking tests such as the 6-minute walk test and modified shuttle walk test have also been used in CF. ${ }^{5,6}$ Although simple to perform, these tests require substantial space and may not be applicable across the lifespan in CF.

The 3-minute step test has been described as an alternative exercise capacity test in children with $\mathrm{CF}^{7-9}$ It involves stepping on and off a single level platform for 3 minutes at a set rate. This test is quick and easy to perform, requires minimal space, and is externally paced. The portable nature of this test makes it suited to the many in-patient, out-patient, and home settings in which adults with $\mathrm{CF}$ receive treatment. In children, the 3-minute step test is reproducible and provokes a greater increase in heart rate and breathlessness than does the 6-minute walk test, and equivalent oxygen desaturation. ${ }^{7}$ It is also responsive to change over the course of antibiotic treatment in children with CF. ${ }^{9}$ No data have been reported regarding these 3-minute step test variables in adults with CF. In other populations the one-minute post-exercise recovery heart rate following a step test is a reliable measure of cardiorespiratory fitness, ${ }^{10}$ but the utility of this variable has not been explored in CF. At present there is no consensus regarding which variables should be measured during a 3-minute step test in adults with CF.

Although the 3-minute step test is a simple measurement tool, important questions regarding its clinical utility have not been answered. To date, all the studies of the 3-minute step test have been in children, with step height and cadence specifically chosen to suit this younger age group, so it is unclear whether the 3-minute step test is suitable for adults. Because there have been no longerterm studies, it is not known whether the 3-minute step test has predictive value similar to more complex exercise tests. Desaturation during a 12-min-walk test is associated with poorer long-term prognosis in children with $\mathrm{CF},{ }^{11}$ but it is not known whether desaturation during the 3-minute step test has similar predictive value. To date, the relationship of variables measured during the 3-minute step test to important clinical outcomes such as disease progression, hospitalization, and survival has not been examined.

We aimed to determine the feasibility and acceptability of the 3-minute step test as an exercise capacity test in adults with $\mathrm{CF}$, the physiologic variables that should be recorded during the 3-minute step test, and whether the 3-minute step test predicts clinical outcomes at 12 months.

\section{Methods}

This study was approved by our hospital and university human ethics committees, and all participants gave written informed consent. We prospectively recruited patients from our CF out-patient clinic in The Alfred Hospital, Mel- bourne, Australia. Patients were considered eligible if they had a diagnosis of CF confirmed by clinical criteria and sweat testing or genotype analysis, were $\geq 18$ years old, and had been clinically stable for the past 2 weeks (no signs or symptoms of an exacerbation, such as increased cough, change in sputum, decreased appetite or weight, change in respiratory examination or respiratory rate). ${ }^{12}$ Participants were excluded if they had any comorbidities that prevented exercise testing (eg, unstable cardiac disease, or severe musculoskeletal or neurological impairments affecting the lower limbs).

Participants were studied in the CF out-patient clinic at regular out-patient visits. Prior to the 3-minute step test we recorded $\mathrm{S}_{\mathrm{pO}_{2}}$ (Onyx II 9550, Nonin Medical. Plymouth, Minnesota) with the subject in the seated position, and resting heart rate (RS400, Polar Electro, Kempele, Finland). Supplemental oxygen was not administered during the test. We recorded the time at which the participant last took albuterol, and if this was more than 2 hours prior to testing, the subject was asked to take 4 puffs of albuterol via metered-dose inhaler and mouthpiece.

The step test involved stepping up onto and down off of a 15-cm step for 3 minutes, per the previously described protocol for children with CF. ${ }^{7}$ Stepping occurred at 30 steps per minute, with the cadence controlled by a metronome. The participant was instructed to place the full foot on the step in each step up. The leading leg was changed each minute, to reduce localized muscle fatigue. A short practice session was performed prior to the test, and standardized instructions and encouragement were given.

We measured $\mathrm{S}_{\mathrm{pO}_{2}}$ continuously throughout the test. The test was discontinued if $\mathrm{S}_{\mathrm{pO}_{2}}$ fell below $80 \% .^{7}$ The participant could terminate the test if he or she became too fatigued or breathless to continue. We recorded the time at which the test ceased and the total number of steps. At 3 minutes the participant was asked to rate his or her breathlessness and leg fatigue on the Borg scale. ${ }^{13}$ After the test we recorded $\mathrm{S}_{\mathrm{pO}_{2}}$ once a minute for 3 minutes. Following the test we downloaded the $\mathrm{S}_{\mathrm{pO}_{2}}$ and heart rate to a computer. The minimum $\mathrm{S}_{\mathrm{pO}_{2}}$, maximum heart rate, and one-minute post-test recovery heart rate were recorded. Desaturation was defined as $\mathrm{S}_{\mathrm{pO}_{2}}<90 \%$ during the test. ${ }^{14}$ To establish the most useful desaturation threshold, we repeated the analyses with desaturation defined as an $\mathrm{S}_{\mathrm{pO}_{2}}$ decrease of $>4 \%$ from baseline. ${ }^{7}$

To quantify the acceptability of the test, participants were asked, "How difficult did you find this exercise test?" Responses were recorded on a $10-\mathrm{cm}$ visual analog scale with the anchors "Not difficult at all, the easiest exercise I have ever performed" and "Extremely difficult, the hardest exercise I have ever performed".

We recorded lung function, height, weight, CF genotype, and sputum colonization at baseline. Lung function tests were performed on the same day as the 3-minute step 
test and we classified impairment as mild ( $\mathrm{FEV}_{1} 60-79 \%$ of predicted), moderate ( $\mathrm{FEV}_{1} 41-59 \%$ of predicted), or severe $\left(\mathrm{FEV}_{1} \leq 40 \%\right.$ of predicted). ${ }^{15}$ Twelve months following the 3-minute step test we again conducted lung function testing and recorded the number of hospital admissions and hospital days during the past 12 months. If a participant had been transplanted or was deceased at the end of 12 months, this was also recorded.

\section{Statistical Analyses}

To assess the relationships between $\mathrm{S}_{\mathrm{pO}_{2}}$, heart rate, and clinical variables at baseline, we calculated the Spearman correlation coefficients $\left(r_{S}\right)$. We examined differences in test performance between those with mild, moderate, and severe lung disease with univariate analysis of variance. We assessed the usefulness of the 3-minute step test to predict clinical outcomes at 12 months with stepwise multiple linear regression analysis, using change in respiratory function and total hospital days (in-patient and hospital in the home days) as dependent variables, and oxygen desaturation to $<90 \%$ as a predictor. Other predictor variables we selected a priori were age, sex, and body mass index (BMI), because these factors are known to influence long-term outcomes in CF. Variables that were not significant were removed from the model, using a probability of F to remove those $\geq 0.200$. Hospital days were not normally distributed and were transformed to natural logarithms. We report the results as the total percentage of variance in the dependent variable that could be explained by the regression model $\left(\mathrm{R}^{2}\right)$, the relative proportion of that variance that could be attributed to each of the predictor variables (partial $\mathrm{R}^{2}$ ), and unstandardized coefficients for the predictors, together with their standard errors. We also repeated the regression analyses with the alternative definition of desaturation $\left(\mathrm{S}_{\mathrm{pO}_{2}}\right.$ decrease of $>4 \%$ from baseline). A $P$ value of $<.05$ was considered statistically significant. All the analyses were undertaken with statistics software (SPSS 17.0, SPSS, Chicago, Illinois).

\section{Results}

We recruited 101 adults (56 males) with CF between April 2007 and March 2008 (Table 1). This represented $43 \%$ of the total clinical population. Twenty-two participants had severe CF lung disease, 34 had moderate disease, 22 had mild disease, and 23 had normal lung function. Forty percent of the participants were homozygous for DF508, and 91\% were colonized with Pseudomonas aeruginosa. There were no significant differences between the sample and the clinic population for the distribution of age, sex, lung function, or BMI.
Table 1. Subjects $(n=101)^{*}$

\begin{tabular}{|c|c|c|}
\hline & Mean \pm SD & Range \\
\hline Age (y) & $29.1 \pm 9.3$ & $18-63$ \\
\hline $\mathrm{FEV}_{1} \%$ predicted & $61 \pm 23$ & $23-122$ \\
\hline FVC $\%$ predicted & $80 \pm 20$ & $14-131$ \\
\hline $\mathrm{FEV}_{1} / \mathrm{FVC}(\%)$ & $63 \pm 14$ & $37-95$ \\
\hline BMI $\left(\mathrm{kg} / \mathrm{m}^{2}\right)$ & $22.2 \pm 4.2$ & $14.1-51.3$ \\
\hline Resting $\mathrm{S}_{\mathrm{pO}_{2}}(\%)$ & $95 \pm 2$ & $89-100$ \\
\hline $\begin{array}{l}* 56 \text { males. } \\
\text { FVC }=\text { forced vital capacit } \\
\text { BMI }=\text { body mass index }\end{array}$ & & \\
\hline
\end{tabular}

\section{Response to the 3-Minute Step Test at Baseline}

Ninety-seven participants completed the entire 3-minute step test. All 4 non-completers had severe lung disease. Reasons for non-completion were excessive dyspnea (3 patients) and leg fatigue (1 patient). There were no adverse events and the test was well tolerated, with a median visual-analog-scale difficulty score of $1.2(0-9.1)$ and a median Borg dyspnea score of 3.0, which indicates moderate dyspnea (range $0-8$ ). Greater difficulty performing the 3-minute step test was associated with a lower percent-ofpredicted $\mathrm{FEV}_{1}\left(\mathrm{r}_{\mathrm{S}}=0.40, P<.001\right)$ and older age $\left(\mathrm{r}_{\mathrm{S}}=0.24, P=.02\right)$. A lower percent-of-predicted $\mathrm{FEV}_{1}$ was also associated with more dyspnea at the end of the test $\left(\mathrm{r}_{\mathrm{S}}=-0.46, P<.001\right)$.

Desaturation was common during the 3-minute step test and the mean $\mathrm{S}_{\mathrm{pO}_{2}}$ reduction was $4 \%$ (range $0-13 \%$ ). The nadir $\mathrm{S}_{\mathrm{pO}_{2}}$ was strongly associated with percent-of-predicted $\mathrm{FEV}_{1}(\mathrm{r}=0.75, P<.001)$. Twenty-two participants (22\%) desaturated to $<90 \%$, and all of those patients had moderate or severe lung disease (Fig. 1).

A lower percent-of-predicted $\mathrm{FEV}_{1}$ was also associated with a higher resting heart rate $(\mathrm{r}=-0.25, P=.01)$, higher maximum heart rate $(\mathrm{r}=-0.25, P=.01)$ and a higher one-minute post-test recovery heart rate $(\mathrm{r}=-0.313$, $P=.003)$. There was no relationship between change in heart rate and disease severity. There was little heart-rate response in those with mildly impaired or normal lung function: 26 of 45 participants in those categories did not reach $70 \%$ of their predicted maximum heart rate, compared to $23 \%$ of those with $\mathrm{FEV}_{1}<60 \%$ of predicted.

\section{Relationship Between 3-Minute Step Test and Clinical Changes at 12 Months}

Two participants died during the 12-month period after the 3-minute step test. Spirometry was repeated in the remaining 99 participants at 12 months. The group data showed no significant change in $\mathrm{FEV}_{1}$ at 12 months (mean decrease of $-40 \mathrm{~mL}, 95 \% \mathrm{CI}-90$ to $12 \mathrm{~mL}$ ); however, 


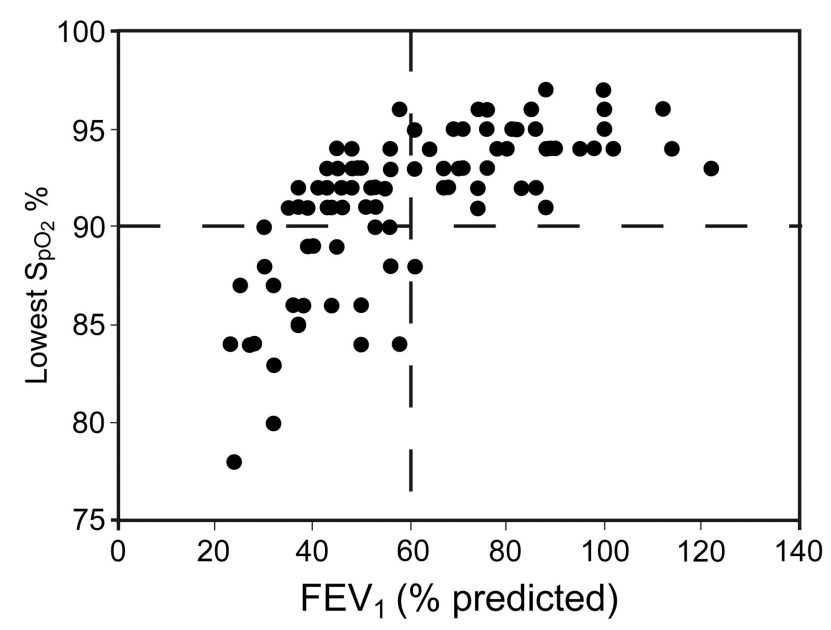

Fig. 1. Nadir $\mathrm{S}_{\mathrm{pO}_{2}}$ during the 3-minute step test versus baseline percent-of-predicted $\mathrm{FEV}_{1}$.

Table 2. Stepwise Multiple Linear Regression Model for Change in FEV $_{1}$ Over 12 Months

\begin{tabular}{lrcrc}
\hline \hline & B & $\begin{array}{c}\text { Standard } \\
\text { Error of B }\end{array}$ & $P$ & $\begin{array}{c}\text { Partial } \\
\mathrm{R}^{2 *}\end{array}$ \\
\hline Constant & 0.236 & 0.073 & .002 & - \\
Baseline $\mathrm{FEV}_{1}$ & -0.104 & 0.028 & $<.001$ & 0.053 \\
$\begin{array}{l}\mathrm{S}_{\mathrm{pO}_{2}}<90 \% \text { on 3-min } \\
\text { step test }\end{array}$ & -0.224 & 0.065 & .001 & 0.103 \\
& & & &
\end{tabular}

* The partial $\mathrm{R}^{2}$ is the proportion of variation in change in $\mathrm{FEV}_{1}$ (in liters) explained by individual variable. $\mathrm{R}^{2}$ (the proportion of variation in change in $\mathrm{FEV}_{1}$ explained by the model) for the model is 0.16

$\mathrm{B}=$ unstandardized coefficient

there was significant inter-individual variation. Participants who desaturated (nadir $\mathrm{S}_{\mathrm{pO}_{2}}<90 \%$ ) during the 3-minute step test had a greater $\mathrm{FEV}_{1}$ decline at 12 months than those who did not (mean difference $-117 \mathrm{~mL}, 95 \% \mathrm{CI}-215$ to $-19 \mathrm{~mL}$ ). There were no significant relationships between change in $\mathrm{FEV}_{1}$ at 12 months and test completion, dyspnea score, or heart rate response to the 3-minute step test. In a stepwise multiple regression model that included age, sex, BMI, baseline $\mathrm{FEV}_{1}$, and desaturation to $<90 \%$, the only significant predictors of $\mathrm{FEV}_{1}$ decline were baseline $\mathrm{FEV}_{1}$ and desaturation (Table 2). This model explained $16 \%$ of the variation in change in $\mathrm{FEV}_{1}$ at 12 months, with $10 \%$ of this variation explained by desaturation alone. When the regression analysis was repeated with the alternative definition of desaturation $\left(\mathrm{S}_{\mathrm{pO}_{2}}\right.$ decrease of $>4 \%$ from baseline $)$, both baseline $\mathrm{FEV}_{1}$ and desaturation remained significant predictors; however, the model explained less of the change in $\mathrm{FEV}_{1}\left(\mathrm{R}^{2}=0.10\right.$, model not shown).

Participants who desaturated during the 3-minute step test had more hospital days in the ensuing 12 months than those who did not desaturate (median $28 \mathrm{~d}$ vs $11 \mathrm{~d}, P<.001$ ).
Table 3. Stepwise Multiple Linear Regression Model for Natural Log of Total Hospital Days Over 12 Months

\begin{tabular}{lrccc}
\hline \hline & B & $\begin{array}{c}\text { Standard } \\
\text { Error of B }\end{array}$ & $P$ & $\begin{array}{c}\text { Partial } \\
\mathrm{R}^{2 *}\end{array}$ \\
\hline Constant & 4.077 & 0.405 & $<.001$ & - \\
Baseline $\mathrm{FEV}_{1}$ & -0.790 & 0.157 & $<.001$ & 0.300 \\
$\mathrm{~S}_{\mathrm{pO}_{2}<90 \% \text { on 3-min }}<$ & 0.847 & 0.362 & .02 & 0.037 \\
$\quad$ step test & & & & \\
\hline
\end{tabular}

* The partial $\mathrm{R}^{2}$ is the proportion of variation in change in $\mathrm{FEV}_{1}$ explained by an individual variable. $\mathrm{R}^{2}$ (the proportion of variation in change in $\mathrm{FEV}_{1}$ explained by the model) for the model is 0.34 .

$\mathrm{B}=$ unstandardized coefficient

A similar relationship was seen when comparing those who could not complete the 3-minute step test to those who completed the entire 3 minutes (median $61 \mathrm{~d}$ vs $18 \mathrm{~d}$, $P=.02)$. A higher resting heart rate was associated with more hospital days $\left(\mathrm{r}_{\mathrm{S}}=0.26, P=.01\right)$. There was no relationship between total hospital days and dyspnea score, difficulty score, or heart rate response to 3-minute step test.

In a stepwise multiple regression model that included age, sex, BMI, resting heart rate, baseline $\mathrm{FEV}_{1}$ and desaturation, the only significant predictors of total hospital days were baseline $\mathrm{FEV}_{1}$ and desaturation to $<90 \%$ (Table 3). This model explained $34 \%$ of the variation in hospital days, of which $4 \%$ was attributable to desaturation alone. When the regression analysis was repeated with the alternative definition of desaturation $\left(\mathrm{S}_{\mathrm{pO}_{2}}\right.$ decrease of $>4 \%$ from baseline), desaturation was no longer a significant predictor of hospital days, and the model explained less of the variance $\left(\mathrm{R}^{2}=0.30\right.$, model not shown).

\section{Discussion}

This study shows that the 3-minute step test is a feasible and acceptable test for adults with CF. Oxyhemoglobin saturation and heart rate response are associated with disease severity, with little heart rate response evident in patients with mildly impaired or normal lung function. Oxyhemoglobin desaturation and $\mathrm{FEV}_{1}$ are independent predictors of decline in lung function and hospital days at 12 months. These results suggest that desaturation to $<90 \%$ during the 3-minute step test may be a useful indicator of risk of clinical deterioration in patients with moderate to severe disease, although the test gives little information in those with better preserved lung function.

Although the 3-minute step test has been evaluated extensively in children, ${ }^{7-9,16}$ there have been few data regarding its utility in adults with CF. The current study shows that the test was acceptable to adults and could be performed by almost all participants, regardless of disease 
severity. Physiological responses to the 3-minute step test were similar to those reported in 54 children with $\mathrm{CF}$ and similar disease severity, ${ }^{7}$ with comparable changes in oxyhemoglobin saturation, heart rate, and dyspnea scores. This suggests that it may be feasible to use the 3-minute step test across the lifespan in CF.

Our results suggest that oxyhemoglobin saturation may be the most important outcome measurement for the 3-minute step test. As well as being a sensitive marker of disease severity, desaturation to $<90 \%$ was an independent predictor of change in both $\mathrm{FEV}_{1}$ and hospital days. Desaturation to $<90 \%$ explained more of the change in $\mathrm{FEV}_{1}$ at 12 months than did baseline $\mathrm{FEV}_{1}(10 \%$ vs $6 \%)$. This result is consistent with previous reports of a strong relationship between desaturation during exercise testing, disease progression, and survival in patients with $\mathrm{CF}^{11}$ and other chronic lung diseases. ${ }^{17,18}$ This may reflect greater ventilation/perfusion mismatch and intrapulmonary shunt in patients with more advanced CF. ${ }^{19}$ However, when desaturation was defined as $>4 \%$ decrease from baseline $\mathrm{S}_{\mathrm{pO}_{2}}$, this relationship with prognosis was no longer evident. It is likely that use of a threshold value of $\mathrm{S}_{\mathrm{pO}_{2}}$ $<90 \%$ identifies a group with lower absolute oxyhemoglobin saturation during exercise and may reflect a greater impairment of the pulmonary vasculature, thought to occur frequently in end-stage CF. ${ }^{20}$ This highlights the importance of using standardized definitions for desaturation, in order to compare data across trials.

It is important that the relationship between desaturation and clinical decline can be detected with a simple field exercise test that is widely applicable and easy to administer. This allows important information about prognosis to be easily accessible to clinicians across the wide variety of settings where people with $\mathrm{CF}$ receive care. Although the proportion of variance at 12 months that could be explained by the regression models was small, desaturation provided additional information about prognosis that was not available from $\mathrm{FEV}_{1}$ alone. Thirty-five participants with $\mathrm{FEV}_{1}<60 \%$ did not desaturate (see Fig. 1); our data suggest that those individuals are less at risk of clinical deterioration than others with moderate to severe disease. This may be useful information for the treating team.

Although heart rate and dyspnea scores were associated with disease severity at baseline, these variables did not predict outcomes at 12 months. Recent data from a retrospective study suggest that resting heart rate may be more important than heart rate response to exercise, and there is a significant relationship between resting sinus tachycardia and mortality in individuals with advanced CF. ${ }^{21} \mathrm{Al}-$ though we found an association between resting heart rate and hospital days, this was not a significant predictor of clinical deterioration. Despite the lack of association between heart rate or dyspnea score and longer term outcomes, these variables are sensitive to change following intravenous antibiotic treatment in children with CF. ${ }^{9}$ These variables may therefore be more suited to evaluating change following an intervention.

It is evident from this study that the 3-minute step test has both floor and ceiling effects. Four participants were not able to complete the test, indicating that the load applied may be too great for those with advanced disease. However, all 4 of those participants desaturated to $<90 \%$ during the test, so clinically relevant information was still obtained despite the shortened test duration. The ceiling effect is likely to be of greater clinical importance. The heart rate response to the 3-minute step test in those with mild disease indicates that the test imposed little cardiovascular load, with more than half of these participants failing to achieve $70 \%$ of their maximum predicted heart rate. This is consistent with the findings of a previous study in children with mild CF lung disease, ${ }^{8}$ which found that clinically relevant desaturation during an incremental exercise test was not detected by a 3-minute step test. Our data confirm that the 3-minute step test is most useful as a screening tool for those at risk of clinical deterioration, but provides little information about those who are not classified as at risk.

An additional limitation of the 3-minute step test is that the work imposed by the test is unknown. No studies have quantified the percentage of peak oxygen uptake during the test by comparison with a maximal test of exercise capacity. The test load is not constant across individuals because of the varying relationship between leg length, body weight, and the fixed $15 \mathrm{~cm}$ step height. Because of these factors the 3-minute step test is not useful for prescription of exercise training work rates. Regular exercise therapy is an integral part of CF management, ${ }^{2}$ so other exercise tests, such as the modified shuttle walk test or an incremental exercise test on a cycle ergometer, will be required to prescribe safe and effective training loads. A further limitation is the lack of data regarding the reproducibility of the 3-minute step test in adults with $\mathrm{CF}$, which we did not investigate. Although previous data indicate that the 3-minute step test has acceptable reliability in children with $\mathrm{CF},{ }^{7}$ further research with adults is needed.

\section{Conclusions}

The 3-minute step test is a feasible and acceptable test of exercise performance in adults with CF. Oxyhemoglobin saturation appears to be the most useful outcome to record, with desaturation to $<90 \%$ being associated with greater $\mathrm{FEV}_{1}$ decline and more hospital days in the following 12 months. The 3-minute step test appears to be less useful in adults with normal or mildly decreased lung function. Our results provide a preliminary rationale for use of the 3-minute step test as a screening tool in CF clinics. Further investigation of the utility of the 3-minute 


\section{Desaturation During the 3-Minute Step Test}

step test over and above routine pulmonary function measurements is needed, along with more information regarding the ability of this simple test to predict clinical outcomes in adults with $\mathrm{CF}$.

\section{REFERENCES}

1. Nixon PA, Orenstein DM, Kelsey SF, Doershuk CF. The prognostic value of exercise testing in patients with cystic fibrosis. N Engl J Med 1992;327(25):1785-1788.

2. Yankaskas JR, Marshall BC, Sufian B, Simon RH, Rodman D. Cystic fibrosis adult care: consensus conference report. Chest 2004; 125(1 Suppl):1S-39S

3. The CF Trust's clinical standards and accreditation group. Standards for the clinical care of children and adults with cystic fibrosis in the UK. Cystic Fibrosis Trust 2001. Available from: http://www.cftrust. org.uk / aboutcf / publications / consensusdoc /C_3000Standards_of_ Care.pdf. Accessed June 10, 2011.

4. Physiotherapy for cystic fibrosis in Australia: a consensus statement. http://www.thoracic.org.au/documents/papers/physiotherapyforcf. pdf. Accessed June 10, 2011.

5. Kadikar A, Maurer J, Kesten S. The six-minute walk test: a guide to assessment for lung transplantation. J Heart Lung Transplant 1997; 16(3):313-319.

6. Bradley J, Howard J, Wallace E, Elborn S. Reliability, repeatability, and sensitivity of the modified shuttle test in adult cystic fibrosis. Chest 2000;117(6):1666-1671.

7. Balfour-Lynn IM, Prasad SA, Laverty A, Whitehead BF, Dinwiddie R. A step in the right direction: assessing exercise tolerance in cystic fibrosis. Pediatr Pulmonol 1998;25(4):278-284.

8. Narang I, Pike S, Rosenthal M, Balfour-Lynn IM, Bush A. Threeminute step test to assess exercise capacity in children with cystic fibrosis with mild lung disease. Pediatr Pulmonol 2003;35(2):108113.

9. Pike SE, Prasad SA, Balfour-Lynn IM. Effect of intravenous antibiotics on exercise tolerance (3-min step test) in cystic fibrosis. Pediatr Pulmonol 2001;32(1):38-43.
10. Santo AS, Golding LA. Predicting maximum oxygen uptake from a modified 3-minute step test. Research quarterly for exercise and sport 2003;74(1):110-115.

11. Aurora P, Wade A, Whitmore P, Whitehead B. A model for predicting life expectancy of children with cystic fibrosis. Eur Respir J 2000;16(6):1056-1060.

12. Goss $\mathrm{CH}$, Burns JL. Exacerbations in cystic fibrosis. 1: Epidemiology and pathogenesis. Thorax 2007;62(4):360-367.

13. Borg G. Psychophysical bases of perceived exertion. Med Sci Sports Exerc 1982;14(5):377-381.

14. British Thoracic Society Standards of Care Subcommittee on Pulmonary Rehabilitation. Pulmonary rehabilitation. Thorax 2001; 56(11):827-834.

15. Frangolias DD, Holloway CL, Vedal S, Wilcox PG. Role of exercise and lung function in predicting work status in cystic fibrosis. Am J Respir Crit Care Med 2003;167(2):150-157.

16. Aurora P, Prasad SA, Balfour-Lynn IM, Slade G, Whitehead B, Dinwiddie R. Exercise tolerance in children with cystic fibrosis undergoing lung transplantation assessment. Eur Respir J 2001;18(2): 293-297.

17. Lama VN, Flaherty KR, Toews GB, Colby TV, Travis WD, Long Q, et al. Prognostic value of desaturation during a 6-minute walk test in idiopathic interstitial pneumonia. Am J Respir Crit Care Med 2003; 168(9):1084-1090.

18. Swigris JJ, Zhou X, Wamboldt FS, du Bois R, Keith R, Fischer A, et al. Exercise peripheral oxygen saturation $\left(\mathrm{S}_{\mathrm{pO} 2}\right)$ accurately reflects arterial oxygen saturation $\left(\mathrm{S}_{\mathrm{aO} 2}\right)$ and predicts mortality in systemic sclerosis. Thorax 2009;64(7):626-630.

19. Dantzker DR, Patten GA, Bower JS. Gas exchange at rest and during exercise in adults with cystic fibrosis. Am Rev Respir Dis 1982; 125(4):400-405.

20. Henno P, Maurey C, Danel C, Bonnette P, Souilamas R, Stern M, et al. Pulmonary vascular dysfunction in end-stage cystic fibrosis: role of NF-kappaB and endothelin-1. Eur Respir J 2009;34(6):1329-1337.

21. Ketchell RI, Roughton M, Agent P, Gyi K, Hodson ME. Predicting survival in end-stage cystic fibrosis. Respir Med 2009;103(10):14411447. 